\title{
De las Juntas Republicanas a la Unión Republicana. Colombia 1908-1910
}

\section{From Republican Juntas to the Republican Union. Colombia 1908-1910}

\author{
Claudia Liliana Monroy Hernández \\ (D) https://orcid.org/0000-0002-0708-0889 \\ Universidad Pedagógica y Tecnológica de Colombia, Colombia \\ climohe@gmail.com
}

\section{Olga Yanet Acuña Rodríguez \\ (D) https://orcid.org/0000-0001-6273-2715 \\ Universidad Pedagógica y Tecnológica de Colombia, Colombia olgayanet@gmail.com}

Resumen: El propósito de este artículo es comprender el origen y la naturaleza de las Juntas Republicanas en Colombia entre 1908 y 1910, creadas entre líderes del liberalismo y del conservatismo en oposición al gobierno de Rafael Reyes, estableciendo una red de información y comunicación, que por una parte se unía para cuestionar la labor del gobernante, mientras se diseñaban actividades para las elecciones de 1909, en las que se debían elegir senadores y representantes. Entre estos líderes circularon ideas de conciliación y tolerancia política, democracia, antiautoritarismo, progreso y modernización del país, que motivaron la salida del presidente Rafael Reyes en 1909, y la consolidación de un proyecto político alternativo denominado "Unión Republicana". La red de información y comunicación o sociabilidad política permitió

cómo citaR: Monroy Hernández, C. L. y Acuña Rodríguez, O. Y. (2021). De las Juntas Republicanas a la Unión Republicana. Colombia 1908-1910. Secuencia (109), e1717. DoI: https://doi.org/10.18234/secuencia. v0i109.1717 
establecer vínculos que se consolidaron entre los diversos actores a través de la prensa, la correspondencia, libros y revistas, en la defensa de un proyecto de conciliación, tolerancia y modernidad política.

Palabras clave: Juntas Republicanas; Unión Republicana; modernidad política.

Abstract: The purpose of this article is to understand the origin and nature of the Republican Juntas in Colombia between 1908 and 1910, created by the leaders of liberalism and conservatism in opposition to the government of Rafael Reyes, establishing an information and communication network, which, on the one hand, joined forces to question the work of the ruler, and on the other devised activities for the 1909 elections, in which senators and representatives were to be elected. Ideas of political conciliation and tolerance, democracy, anti-authoritarianism, progress, and modernization of the country circulated among these leaders, which led to the departure of President Rafael Reyes in 1909, and the consolidation of an alternative political project known as the "Republican Union". The information and communication network or political sociability made it possible to establish links that were consolidated between the various actors, through the press, correspondence, books, and journals, to defend a project of conciliation, tolerance, and political modernity.

Key words: Republican Juntas; Republican Union; Political Modernity.

Recibido: 22 de febrero de 2019 Aceptado: 3 de abril de 2020

Publicado: 3 de marzo de 2021

\section{INTRODUCCIÓN}

$\mathrm{E}_{\text {colombiana como un periodo más de la hegemonía conservadora (1886- }}^{\text {l republicanismo (1908-1918) del siglo xx aparece en la historiografía }}$ 1930), en el que se analiza la influencia que tuvo el partido conservador en 
la salida del presidente Rafael Reyes del poder en $1909,{ }^{1}$ la reforma constitucional de 1910 y la coalición bipartidista. ${ }^{2}$ En algunos casos el debate gira en torno a si el republicanismo fue o no un partido político, tomando como referencia su corta existencia y situándolo en el periodo comprendido entre 1910 y 1914, particularmente con el periodo presidencial de Carlos E. Restrepo (Brugman, 2001), así como otros trabajos de carácter regional que resaltan la forma como se dinamizó la política en Barranquilla entre 1910 y 1914 a partir del proyecto de la Unión Republicana (Álvarez, 1995) y el republicanismo en el Valle del Cauca 1880-1920 (Flórez, 1997). Sin embargo, la historiografía ha omitido aspectos relacionados con el proyecto político que lideraron los republicanos, el cual estaba articulado con el impulso de sus negocios y de sus regiones, bajo una idea general de modernización, de la cual se deriva el fortalecimiento del régimen democrático, en oposición al autoritarismo implementado por el presidente Rafael Reyes (1904 y 1909).

El propósito de este artículo es analizar las redes de información y comunicación que se crearon, a partir de 1908, entre líderes de los partidos liberal y conservador, las cuales dieron origen a la creación de las Juntas Republicanas en Colombia, que en principio se consolidaron en oposición al gobierno de Rafael Reyes y luego se organizaron y establecieron como movimiento político, bajo el nombre de Unión Republicana. El republicanismo estaba integrado por representantes de distintos departamentos que crearon vínculos muy fuertes, no sólo en lo económico y político, sino desde su cotidianidad y sus ideas de progreso, tolerancia, conciliación y paz política.

Esta investigación está inscrita en el campo de la historia política, bajo un enfoque hermenéutico, que pretende poner en diálogo las distintas fuentes e interpretar el lenguaje a través de sus actores, ideas, proyectos y discursos, vistos en la prensa y la correspondencia. Se centra en la sociabilidad política, la cual se relaciona con la opinión pública ejercida por los ciudadanos, que como lo menciona Maurice Agulhon (2009, p. 207) existe desde una relación entre lo cívico y lo político, entre la vida privada y la vida de círculo, permitiendo responder a algunas de las interrogantes planteadas por la política. En el caso de la Unión Republicana, se refiere a los nexos que se crearon entre

\footnotetext{
${ }^{1}$ Una visión descriptiva como la que contienen los trabajos de Jorge Orlando Melo (1989) y Darío Mesa (1982).

${ }^{2}$ Los estudios desde la ciencia política y el análisis de la reforma constitucional de 1910 que hace Javier Duque (2011); Rafael Rubiano Muñoz (2011); Fernando Correa (1996); Olga Yanet Acuña (2017).
} 
los líderes y que obedece a vínculos de procedencia, económicos, amistad y filiación política, que los llevaron a asociarse, organizarse y corresponder a un proyecto conjunto.

Para Loaiza (2016) "la sociabilidad fue la matriz generadora de acciones colectivas con la que grupos más o menos organizados de individuos pretendieron ejercer algún grado de influencia pública" (p. 193), en este caso se trató de contrarrestar el poder del Estado y sus prácticas dictatoriales, desde la difusión de ideas y experiencias modernizantes, a partir de "vínculos" como los que menciona Guerra (1989, p. 249), de parentesco, de clientela o de amistad, a los cuales les otorga un contenido distinto, según la época, y regulado por la costumbre y la pertenencia a un grupo según el oficio que se ejerce. Así, los negocios, la vida periodística, los intereses políticos regionales, las asociaciones a las que pertenecían, además de una serie de valores y principios llevaron a consolidar el movimiento republicano en distintos lugares del territorio nacional, especialmente en Medellín y Bogotá.

Se trató de individuos que se iban sumando a la Unión Republicana y que no necesariamente se acogían bajo un principio de fidelidad, sino por distintas condiciones e intereses, sin que esto los obligara a renunciar a sus valores tradicionales, a sus costumbres en la vida familiar, religiosa o privada, en general. Según Guerra (1989), "los comportamientos públicos cambian antes que los privados" y "su influencia política resulta más de su capacidad de acción antigua que de la adhesión a la política moderna que formulan" (p. 262). Asimismo, Furet (1978, p. 55) menciona que el mundo de la sociabilidad política está estructurado a partir del individuo y no de sus grupos institucionales, basado en la opinión que se produce en los cafés, en los salones, en los palcos y en las "sociedades". A estas relaciones le da el nombre de sociabilidad democrática, aun teniendo en cuenta que esta no logra extenderse a todo el pueblo, sin embargo, logra establecer nuevos valores y reglas de juego que tienen en cuenta a un mayor número de sujetos.

A continuación se hará alusión al surgimiento de las Juntas Republicanas en el contexto del gobierno de Rafael Reyes, a las redes de información y comunicación que se establecieron y que dieron origen a la Unión Republicana; asimismo a las formas de sociabilidad que dinamizaron la expansión de las ideas de progreso, tolerancia y conciliación que proyectaron una idea de modernidad política. 


\section{EL GOBIERNO DE RAFAEL REYES}

Después de la guerra de los Mil Días y por las profundas crisis política y económica que vivió el país, los colombianos eligieron a Rafael Reyes Prieto como presidente en 1904. Este destacado personaje conservador se había desempeñado como militar en la guerra de 1885, como senador en 1890, y participó en la guerra de 1895; en este mismo año como ministro en el gobierno de Miguel Antonio Caro, y en tiempos de la guerra de los Mil Días como delegado de Colombia en París. Su corta trayectoria diplomática le trazó un rumbo importante en la escena política y muchos vieron en este personaje una figura importante para superar la crisis. Su proyecto de gobierno, orientado en dos pilares -orden y autoridad-fue visto como la esperanza para alcanzar el progreso económico.

Rafael Reyes planteó la necesidad de orientar su gobierno hacia la intervención del Estado para superar la crisis económica y fiscal, razón por la cual le solicitó al Congreso concederle facultades especiales bajo un proyecto titulado "Autorizaciones al Poder Ejecutivo", las cuales no le fueron aprobadas (Sanín Cano, 2015, p. 24), razón por la cual Reyes decidió clausurar el Congreso el 13 de diciembre de $1904^{3}$ y convocar una Asamblea Nacional Constituyente.

Esta Asamblea Nacional fue convocada por el presidente Reyes a razón de tres representantes por cada uno de los nueve departamentos, uno por cada partido en que estaba dividido el país: conservador histórico, conservador nacionalista y liberal. Fue convocada para el 1 de febrero de $1905^{4}$ e instalada el 15 de marzo del mismo año y legisló hasta 1909, sin embargo, quedó sujeta al ejecutivo produciendo un desequilibrio en los tres poderes públi$\cos$, con diputados aparentemente nombrados por una junta que presidía el gobernador, pero que en realidad eran nombrados por el mismo presidente Reyes y se reunía sólo cuando este la convocaba, dando como resultado que

${ }^{3}$ Mensaje Presidencial. 13 de diciembre de 1904. Bogotá.

${ }^{4}$ Decreto 29 de 1905. 1 de febrero de 1905. Diario Oficial, año XLI, núm. 12280.

${ }^{5}$ Por el cual se sustituye el artículo 209 de la Constitución. La Asamblea Nacional Constituyente y Legislativa de Colombia. DeCRETA: "Art. $1^{\circ}$. La Constitución de la República podrá ser reformada por una Asamblea Nacional convocada expresamente para este objeto por el Congreso, o por el Gobierno Ejecutivo, previa solicitud de la mayoría de las municipalidades. Acto legislativo núm. 9, 17 de abril de 1905. Diario Oficial, año XLI, núm. 12337. 
"todos los decretos legislativos dictados por el general Reyes fueron aprobados incondicionalmente"(Restrepo, 1972, p. 348).

Entre las leyes implementadas se encontraba la eliminación de la vicepresidencia y la ampliación del periodo presidencial a diez años, solo para el mandato del presidente Reyes; ${ }^{6}$ se aprobó la ley de minorías que consistía en darle participación a un liberal por cada tres conservadores y cuyo objetivo era mantener las proporciones de los partidos en el poder y así conservar buenas relaciones con el liberalismo. Según Lina Adarve (2010) "con esta ley lo que se hizo fue vincular a algunos liberales a título personal, ocasionando rencillas y divisiones entre los miembros del mismo partido", mientras que "los conservadores que hicieron parte de la administración pública fueron reconocidos como reyistas" (p. 70).

Además, se aprobó la ley de alta Policía Nacional, ${ }^{7}$ que significó el fortalecimiento de la autoridad militar en todo el país y un control más fuerte sobre cada uno de los departamentos; la ley 13 de 1908 sobre orden público, ${ }^{8}$ en la que se estableció la pena de muerte por delitos políticos e, incluso, la censura de prensa bajo el argumento de "impedir que se use como elemento desmoralizador o como arma de rebelión". ${ }^{9}$ Por otra parte, la Asamblea Nacional determinó el periodo de los magistrados y su nombramiento, ${ }^{10} \mathrm{el}$ cual tenía toda la influencia y decisión del presidente de la República, demostrando con estas medidas legislativas el objetivo real que tenían de posicionar al ejecutivo por encima de los demás poderes, dentro de un claro centralismo y autoritarismo.

De acuerdo con Suárez Mayorga (2017), "la opinión pública que inicialmente había respaldado a Rafael Reyes, acabó convirtiéndose en una de las principales detractoras de su gestión, situación que propició que para principios de 1909 en los diarios de la época se le calificara abiertamente de dictador" (p. 121). Reyes buscaba, a como diera lugar, ejercer todo el dominio y control nacional desde la presidencia de la República, en ese sentido no

${ }^{6}$ Acto Legislativo núm. 5 de 1905, 30 de marzo de 1905. Anales de la Asamblea Nacional, núm. 21, 10 de mayo de 1905, p. 161. Bogotá.

${ }^{7}$ Decreto 11 de 1906. 5 de febrero de 1906. Diario Oficial, año XLII, núm. 12564.

${ }^{8}$ Ley 13 de 1908. 18 de agosto de 1908. Diario Oficial, año MCMviII, núm. 13371.

9 Anales de la Asamblea Nacional, núm. 3, 29 de marzo de 1905, p. 1. Bogotá.

${ }_{10}$ Acto reformatorio núm. 1 de 1905. 27 de marzo de 1905. Diario Oficial, año xLI, núm. 12314. 
le importaba que lo llamaran dictador, mientras encontrara el camino para sacar adelante sus proyectos.

Ante esta serie de reformas e imposiciones presidenciales, se amplió el grupo de opositores al gobierno, mientras que los republicanos de Bogotá y Antioquia entablaron diálogos permanentes con líderes políticos de otras regiones del país, en donde importantes personajes de la vida política ya se mostraban en desacuerdo con el presidente Reyes.

Esta situación también se hizo evidente en el exterior, donde líderes políticos como Pedro Nel Ospina y Santiago Pérez Triana seguían la política nacional muy de cerca. Por ejemplo, Santiago Pérez Triana, desde Londres, planteó que "el gobierno de Reyes es decididamente incoherente y pernicioso y terminará por llevar al país a la absoluta miseria". ${ }^{11}$ Escritos que no pasaban desapercibidos ante los ojos del gobierno y que nutrían el discurso de La Unión Republicana, especialmente de los antioqueños liderados por Carlos E. Restrepo, quienes en el escenario nacional lanzaban acusaciones constantemente. Así como los republicanos de Cartagena, que señalaban al presidente por "querer aprobar tratados bajo la presión de la fuerza y habiendo motivos para pensar que recibió un anticipo del gobierno de Estados Unidos para que fueran aprobados". ${ }^{12}$ Estos señalamientos agitaban a la oposición, que a través de la prensa aludía al gobierno como inconstitucional y autoritario.

Fue así como el periódico Zigzag de Bogotá, de tendencia republicana, lo presentó como "gobierno inconstitucional y culpable de dejar al país en ruinas". Además, promovían su salida con argumentos basados en la forma como había sido elegido: "está probado que Reyes no tuvo ni la tercera parte de los votos de Vélez, sino que fue por un robo de boletas cometido en el escrutinio de 1904, ordenado por el extinto presidente Marroquín". ${ }^{13}$ Este acontecimiento conocido por la historiografía como el "registro de Padilla", en el que "se le escamoteó la presidencia al general Joaquín F. Vélez, candidato cartagenero de los conservadores históricos" (Sourdis, 2017, p. 21), fue aprovechado para hacer oposición y aumentar el discurso de deslegitimación al presidente Reyes.

${ }^{11}$ Carta de Santiago Pérez Triana, 21 de noviembre de 1908. Correspondencia Recibida. Caja 9, f. 7, París. Archivo Carlos E. Restrepo-Biblioteca Universidad de Antioquia (en adelante ACER-BUdEA), Colombia.

12 Carta Republicanos de Cartagena, 17 de mayo de 1909. Correspondencia recibida. Caja 10, D68, fs. 91-92. ACER-BudeA, Colombia.

13 Zigzag, 23 de julio 23 de 1909, Bogotá. 
Por otra parte, en noviembre de 1908 había llegado de Europa el general Pedro Nel Ospina, y en Medellín habían conformado una junta de conservadores dispuestos a luchar por el restablecimiento de las instituciones republicanas. "La reunión se realizó el 24 de noviembre de 1908 con la asistencia de Pedro Nel Ospina, Tulio y Mariano Ospina, Justiniano Macía, Clodomiro Ramírez, Pablo y Pascual Gutiérrez, Bernardo Gómez y Carlos E. Restrepo, en la cual se propuso buscar la unión con elementos liberales y, además, enviar comisionados a Bogotá, Cauca, Santander y la Costa Atlántica" (Correa, 1996, p. 110). Los líderes republicanos de Antioquia buscaron permanentemente la unión con los principales opositores del gobierno de Reyes en Bogotá, especialmente con Guillermo Quintero Calderón y Nicolás Esguerra para unir esfuerzos y llegar a los demás departamentos en donde se esperaba contar con el respaldo de liberales y conservadores, dispuestos a hacer parte de la oposición y elevar solicitudes al gobierno exigiendo el restablecimiento de la democracia y la reunión del Congreso elegido por voto popular.

El movimiento que ya habían empezado los antioqueños vino a tomar fuerza en la capital de la República el 13 de marzo de 1909, cuando una gran manifestación popular en contra de Rafael Reyes sacudió las calles de Bogotá. "Jorge Martínez, joven estudiante, hijo de Carlos Martínez Sílva, habló contra la dictadura delante del mismo Reyes, de igual modo que Enrique Olaya Herrera" (Correa, 1996, p. 114), que ante la presencia de los líderes más notables del liberalismo hacía su entrada a la política, con un discurso vehemente en contra del régimen de Reyes.

Las manifestaciones del 13 de marzo de 1909 tuvieron como resultado la detención de Olaya Herrera y del general Felipe Escobar, quienes fueron llevados a prisión en Cartagena y puestos en libertad hasta el 24 de mayo, por gestión de la Junta Republicana de Medellín. Este hecho generó la solidaridad entre los líderes de Antioquia y de Bogotá, como se observa en el telegrama que estos dos personajes enviaron a la Junta Republicana de Medellín, reconociendo la satisfactoria tarea en favor de su libertad: "la mejor manifestación de nuestro profundo reconocimiento no puede ser otro que la promesa de servir en nuestro modesto esfuerzo a la patria" ${ }^{14}$ Los republicanos de Antioquia y de Bogotá consolidaban cada vez más sus relaciones políticas y estrechaban

${ }^{14}$ Carta de Enrique Olaya Herrera y Felipe Escobar. Correspondencia recibida. 24 de mayo de 1909. D79, f. 108, Cartagena. ACER-BUDEA, Colombia. 
sus lazos de amistad, de negocios y de unión bajo las ideas republicanas, cuya pretención era fortalecerse para las contiendas electorales de mayo de 1909.

Precisamente los acontecimientos del 13 de marzo de 1909 provocaron que ese día el presidente Reyes se sintiera abandonado no sólo por la opinión pública, sino por sus amigos.

Su primera actitud fue renunciar, al tiempo que encargaba a su ministro y pariente Jorge Holguín de la Presidencia de la República. Las primeras medidas tomadas por el mandatario encargado fueron retirar los tratados sometidos a consideración de la Asamblea y decretar el estado de sitio en la capital; pero horas más tarde y alegando evitar la anarquía en el país, Rafael Reyes reasumió el mando, incrementó las medidas represivas e hizo instalar dos ametralladoras en el capitolio (Correa, 1996, p. 115).

Recobrado el orden público, "Reyes presentó renuncia al cargo de Presidente, ante la Asamblea Nacional y esta después de consultar a las municipalidades, no la aceptó" (Correa, 1996, p. 115). Ante esta situación, vino una serie de manifestaciones escritas por parte de los republicanos, quienes consideraban que las consultas a las municipalidades habian sido manipuladas y la renuncia de Reyes no había sido más que una estrategia para apaciguar las protestas del 13 de marzo. Esta manifestación se convirtió en la principal muestra de opinión pública en contra del gobierno, pues allí se reunieron estudiantes, industriales, comerciantes, líderes políticos conservadores y liberales de distintas regiones, que unidos en contra de la "dictadura", generaron una acción colectiva para ejercer presión y desestabilizar el régimen del quinquenio.

\section{ORGANIZACIÓN DE LAS JUNTAS REPUBLICANAS}

Las elecciones para Congreso, desarrolladas en mayo de 1909, fueron el principal motivo para que en distintos municipios y capitales se organizaran las Juntas Republicanas e hicieran alianzas líderes políticos del partido conservador y liberal, que deseaban por una parte ver terminado el gobierno de Rafael Reyes y, por otra, tener una representación en el nuevo Congreso.

Para el caso de Bogotá, el 13 de marzo de 1909 se sitúa como el origen de las Juntas Republicanas, por haberse llevado a cabo una serie de motines 
ocasionados por los tratados con Panamá y Estados Unidos, cuyas manifestaciones terminaron por ser un gran golpe de opinión en contra del gobierno de Reyes, que llevó a que trece días después un grupo de conservadores y liberales encabezados por Guillermo Quintero Calderón, Nicolás Esguerra, Carmelo Arango, Adolfo León Gómez y Daniel J. Reyes fueran encargados para dirigir los trabajos eleccionarios del Congreso como se aprecia en el periódico conservador El Nuevo Tiempo:

Un grupo muy numeroso de ciudadanos residentes en esta capital de origen colombiano, nacidos en diversas localidades de la República y de filiación política diversa, que han hecho parte de los antiguos partidos Conservador, Liberal y Nacionalista, nos ha hecho del modo más espontáneo, el muy alto honor de designarnos para constituir una junta que nosotros le llamaremos republicana, destinada a servir de centro para los trabajos electorales previos o preparatorios de las elecciones de los Senadores y Representantes que habrá de formar el próximo Congreso Constitucional. ${ }^{15}$

La Junta Republicana de Bogotá tuvo como objetivo principal trabajar por unas elecciones en paz y exigir al gobierno medidas que garantizaran el restablecimiento de los derechos de los ciudadanos no sólo en la capital, sino en el resto del país, y además designar miembros para las Juntas Republicanas de los demás departamentos y municipios. Por esta razón, invitaron a los ciudadanos a "formar o promover la formación de juntas departamentales y seccionales" y a "encauzar la opinión de modo tal que las elecciones se efectúen con la mayor regularidad y en el mejor orden, y que los elegidos sea cual fuere o haya sido su filiación política representen la verdadera y actual opinión de los electores" ${ }^{16}$ En este sentido, empezaron por enviarles un telegrama a Juan B. Peláez, Juan Pablo Gómez, César Piedrahita y Carlos E. Restrepo designándolos para "constituir una junta en todo el viejo departamento de Antioquia” (Restrepo, 1972, p. 403), quienes además de trabajar los temas electorales, fueron los responsables de crear y organizar las Juntas Republicanas de sus municipios.

Los republicanos de Antioquia tenían ya una larga trayectoria de oposición al gobierno de Reyes. Al respecto, Jorge Orlando Melo (1989) señala

15 "Junta Republicana de Bogotá", El Nuevo Tiempo, 1 de abril de 1909.

16 "Junta Republicana de Bogotá", El Nuevo Tiempo, 1 de abril de 1909. 
cómo "el conservatismo antioqueño estaba muy ligado al liberalismo local [...] y desde 1904 había estado predicando una coalición que permitiera el regreso a las prácticas civilistas y legalistas, con el reconocimiento de los derechos políticos a ambos partidos" (p. 218), pero además hace referencia a que "en marzo de 1908, 250 notables de Medellín, encabezados por Carlos E. Restrepo y la familia Ospina, expresaron el rechazo de liberales y conservadores locales a Reyes, quien respondió con la prisión de Gonzalo Mejía y otros comerciantes" (p. 218).

Por eso la designación que les hizo la Junta Republicana de Bogotá para organizar la Junta Republicana de Antioquia fue muy bien recibida; y en seguida, un grupo de conservadores antioqueños, entre los que estaban Pedro Nel Ospina, Tulio Ospina, Eduardo Vásquez, y otros, mostraron su deseo de unirse a los republicanos de Medellín para trabajar en las próximas elecciones para Congreso, manifestando a través del periódico República: "procedemos así, sin abdicar ninguna de nuestras ideas políticas y movidos por el deber de evitar el peligro de que los candidatos republicanos de los diversos partidos [...] sean derrotados al detal, por la festinación de las elecciones y la incapacidad en que se hallan las colectividades políticas para reorganizarse y compactarse" ${ }^{17}$ Así quedaron constituidas las Juntas Republicanas de Bogotá y Medellín, las cuales se encargaron de replicar su organización en los diferentes departamentos y municipios del territorio nacional. Según El Republicano de Bogotá, su liderazgo estuvo bajo los personajes pertenecientes a los dos partidos políticos tradicionales, mismos que se muestran en el cuadro 1 .

Es importante mencionar que estas alianzas no fueron solamente entre quienes figuraban en la dirección de las Juntas Republicanas, sino entre muchos que se inscribieron a ellas, buscando representación política, participar en las elecciones, derrocar al presidente, entre otros intereses y motivaciones, sin que esto significara para algunos, renunciar totalmente a sus partidos tradicionales.

Una vez constituidas estas dos Juntas Republicanas, empezaron a organizarse en los demás municipios y departamentos del país, como fue el caso del Atlántico, en donde "La Junta Republicana Nacional, ya conformada, envió una comunicación a los liberales del Atlántico en la que se estimulaba a la conversión de los comités liberales en Juntas Republicanas locales, para que se dedicaran a la coordinación de la campaña electoral" (Álvarez, 1995, p. 31).

${ }^{17}$ República, 30 de abril de 1909, Medellín. 


\section{Cuadro 1. Juntas Republicanas de Bogotá y Medellín}

Junta Republicana de Bogotá

Guillermo Quintero Calderón (conservador), Nicolás Esguerra (liberal), Carmelo Arango (liberal), Daniel J. Reyes (conservador) y Adolfo León Gómez (liberal)
Junta Republicana de Medellín

Carlos E. Restrepo (conservador), César

Piedrahita V. (liberal), Juan Pablo

Gómez O., Juan Bautista Peláez, Eduardo Correa Uribe, Antonio José Montoya y Mariano Ospina Vásquez (conservadores)

Fuente: elaboración propia a partir de información aportada por el periódico El Republicano, 22 de abril de 1909, Bogotá.

Este fue el caso del comité Liberal de Atlántico, el cual logró que "algunos dirigentes conservadores opuestos ya al gobierno de Reyes concertaran con el liberalismo para la conformación de la Junta Republicana local" (Álvarez, 1995, p. 32). La Junta Directiva del Comité Liberal quedó conformada como se muestra en el cuadro 2.

Asimismo ocurrió en Cali, donde el republicanismo era acogido con fuerza por importantes elites políticas que se sumaban al movimiento de oposición en contra del presidente Reyes. "En el comité republicano del partido conservador de Cali de abril 29 de 1909, figuraron Ignacio Palau, Pablo Borrero A., Ignacio A. Guerrero, Manuel Carvajal, Ulpiano González, Manuel M. Caicedo", quienes no se decían abiertamente opositores del gobierno, sino que declaraban "contribuir a las reformas prometidas, pero no cumplidas, redimir la legalidad y prácticas republicanas y contra tendencias absorbentes que habían traído ruina a las provincias" (Flórez, 1997, p. 81).

De esta manera se iban organizando los comités liberales o los comités conservadores, según los que tuvieran más fuerza en cada departamento o municipio. Para el caso de Barranquilla fueron los liberales los que hicieron el tránsito hacia las Juntas Republicanas, mientras que en Cali fueron los conservadores los que organizaron las Juntas Patrióticas o Juntas Republicanas, acogiendo miembros del partido contrario.

Aunque se explica cómo se organizaron las Juntas Republicanas en las principales ciudades, es importante identificar bajo qué elementos se constituyeron las Juntas en los municipios. Por lo tanto, en el cuadro 3 se muestran 
Cuadro 2. Junta Directiva del Comité Liberal del Atlántico, 1909

\begin{tabular}{ll} 
Nombre & \multicolumn{1}{c}{ Cargo } \\
Manuel Z. de la Espriella & Presidente \\
Demetrio Dávila & Vicepresidente \\
Héctor Manuel Baena & Fiscal \\
Julio Vengoechea & Secretario \\
Manuel Cotes & Tesorero \\
Pedro del Real & Suplente \\
Pedro Polo, y otros & Suplentes
\end{tabular}

Fuente: Álvarez (1995, p. 32).

algunos datos de Juntas Republicanas locales, como una muestra del procedimiento efectuado, que nos permite comprender la dinámica a nivel nacional.

Tanto en la constitución de estas Juntas como en otras que registra la prensa y la correspondencia, vemos que en su gran mayoría los miembros principales fueron designados por la Junta Republicana de Bogotá, que figuraba como Junta Republicana Nacional y dirigía los temas eleccionarios en 1909. Sin embargo, no podemos desconocer la importancia y protagonismo que tomó la Junta Republicana de Antioquia no sólo en su departamento, sino en el ámbito nacional, donde convocaron y afianzaron las ideas republicanas. Para el caso de Antioquia, la junta republicana de este departamento fue la que recomendó los candidatos para las Juntas municipales (véase cuadro 4).

Prácticamente en todo el departamento los miembros de las Juntas Republicanas fueron designados por la Junta Departamental, la cual se encontraba en cabeza de Carlos E. Restrepo. En su mayoría quedaron nombrados los miembros que esta Junta referenció para cada municipio y donde hubo algún cambio debieron comunicarlo justificadamente. Donde más y mejor organizadas estuvieron las Juntas Republicanas fue en el departamento de Antioquia de donde se registra gran cantidad de cartas, telegramas y prensa con la Junta Departamental, especialmente con su líder Carlos E. Restrepo, dando cuenta de la forma como establecieron una importante red de comunicación.

Cristopher Abel explica cómo las Juntas Republicanas surgen con mayor fuerza en el departamento de Antioquia, debido a que durante el régimen 


\section{Cuadro 3. Juntas Republicanas Municipales}

\begin{tabular}{|c|c|c|}
\hline & $\begin{array}{l}\text { Lugar } \\
\text { dondese }\end{array}$ & \\
\hline $\begin{array}{l}\text { eccha de } \\
\text { onstitución }\end{array}$ & $\begin{array}{l}\text { creóla Junta } \\
\text { Republicana }\end{array}$ & Descripción del motivo \\
\hline
\end{tabular}

\begin{tabular}{|c|c|c|c|}
\hline $\begin{array}{l}\text { Abril } 16 \\
\text { de } 1909\end{array}$ & Facatativá & $\begin{array}{l}\text { "Nos hemos constituido en esta fecha } \\
\text { en Junta Republicana similar a las } \\
\text { ya existentes en la capital de la repú- } \\
\text { blica y en otros centros importantes } \\
\text { del país con el laudable propósito de } \\
\text { cooperar en las próximas elecciones } \\
\text { populares iniciadas por el supremo } \\
\text { gobierno". }\end{array}$ & $\begin{array}{l}\text { Florentino } \\
\text { Ángulo, Celio } \\
\text { Guzmán Rubio, } \\
\text { Inocencio de la } \\
\text { Torre, Polidoro } \\
\text { Téllez, Teodosio } \\
\text { Correa. }\end{array}$ \\
\hline $\begin{array}{l}\text { Abril } 14 \\
\text { de } 1909\end{array}$ & Neiva & $\begin{array}{l}\text { Señores general Guillermo Quin- } \\
\text { tero Calderón y doctores Nicolás } \\
\text { Esguerra y Carmelo Arango, Bogotá. } \\
\text { Recibimos el telegrama en que se nos } \\
\text { comunica la designación hecha en } \\
\text { nosotros para organizar los trabajos } \\
\text { electorales en este departamento. }\end{array}$ & $\begin{array}{l}\text { Toribio Rivera, } \\
\text { Anselmo Gaitán } \\
\text { U., Augusto } \\
\text { Martínez, Pláci- } \\
\text { do Serrano B. }\end{array}$ \\
\hline $\begin{array}{l}\text { Mayo } 11 \\
\text { de } 1909\end{array}$ & Machetá & $\begin{array}{l}\text { Señores miembros de la Junta Re- } \\
\text { publicana de Bogotá. habiéndose } \\
\text { reunido numeroso personal de este } \\
\text { municipio el } 9 \text { de los corrientes y } \\
\text { confiados en la patriótica circular } \\
\text { del señor general Reyes, para las ga- } \\
\text { rantías que todas las autoridades del } \\
\text { país deben presentar en los trabajos } \\
\text { eleccionarios, se procedió con toda } \\
\text { la cultura y prudencia del caso a } \\
\text { formar la Junta de este lugar. }\end{array}$ & $\begin{array}{l}\text { El presidente Sa- } \\
\text { lomón Romero; } \\
\text { el vicepresi- } \\
\text { dente Rubén } \\
\text { Forero; vocales } \\
\text { Víctor Alberto } \\
\text { Guerrero, Pedro } \\
\text { Segura, Hipólito } \\
\text { Forero. }\end{array}$ \\
\hline
\end{tabular}




\begin{tabular}{|c|c|}
\hline & $\begin{array}{c}\text { Lugar } \\
\text { donde se }\end{array}$ \\
\hline & creó la Junta \\
\hline
\end{tabular}

\begin{tabular}{|c|c|c|c|}
\hline $\begin{array}{l}\text { Abril } 19 \\
\text { de } 1909\end{array}$ & Buga & $\begin{array}{l}\text { El comité departamental de Cartago } \\
\text { representante de la Junta Republi- } \\
\text { cana de Bogotá, se ha dirigido al } \\
\text { doctor Luis F. Campo para que se } \\
\text { organice en esta ciudad una Junta } \\
\text { de la índole de aquella, los abajo } \\
\text { firmantes hemos formado aquí una } \\
\text { Junta Seccional Republicana para } \\
\text { secundar el propósito de trabajar en } \\
\text { las próximas elecciones. }\end{array}$ & $\begin{array}{l}\text { Luis F. Campo, } \\
\text { Francisco Rive- } \\
\text { ra, José Ignacio } \\
\text { Ospina, Emilio } \\
\text { Quintero, Alfon- } \\
\text { so Borrero }\end{array}$ \\
\hline $\begin{array}{l}\text { Abril } 23 \\
\text { de } 1909\end{array}$ & Chiquinquirá & $\begin{array}{l}\text { El } 23 \text { del pasado tuvo lugar una } \\
\text { reunión a la que asistieron más de } \\
\text { cuatrocientas personas de todas las } \\
\text { denominaciones políticas y de lo } \\
\text { más notable de aquella ciudad, de la } \\
\text { que surgió una junta electoral repu- } \\
\text { blicana, compuesta de los siguientes } \\
\text { miembros, personas de alta repu- } \\
\text { tación social, de elevado carácter y de } \\
\text { reconocida honorabilidad política. }\end{array}$ & $\begin{array}{l}\text { General Ramón } \\
\text { Neira (liberal); } \\
\text { general Hipólito } \\
\text { Castaño (conser- } \\
\text { vador); doctor } \\
\text { Belisario Melo } \\
\text { (liberal); doctor } \\
\text { Francisco E. } \\
\text { Páez (conser- } \\
\text { vador); doctor } \\
\text { Nepomuceno } \\
\text { Peña (liberal), } \\
\text { y doctor Julio } \\
\text { Ramón Vargas } \\
\text { (conservador). }\end{array}$ \\
\hline
\end{tabular}

Fuente: elaboración propia a partir de datos encontrados en los periódicos: La Unión Republicana, 23 de abril de 1909, Bogotá; Thalía, 25 de abril de 1909, Bogotá. 


\section{Cuadro 4. Candidatos para Juntas Republicanas de Antioquia}

Municipio Candidatos

$\begin{array}{ll}\text { Andes } & \text { Joaquín González, Laurencio Pérez, Rafael Posada } \\ \text { Bolívar } & \text { Alejandro Vélez, Eugenio Calle, Alberto Uribe } \\ \text { Concordia } & \text { Wecezlan Villa, Rafael Toro, Antonio José González } \\ \text { Salgar } & \text { Carlos Johnson, Domingo Ochoa, Efraín Arroyave } \\ \text { Jardín } & \text { Cipriano Correa, Pablo Echeverri } \\ \text { Caramanta } & \text { Federico Delgado, Telesforo Osorio } \\ \text { Támesis } & \text { Alejandro Vásquez, Adolfo Naranjo, Rafael Aristizábal } \\ \text { Valparaíso } & \text { Jesús Arango, Luis Gómez, Vicente Peláez }\end{array}$

Fuente: elaboración propia a partir de datos encontrados en carta de Carlos E. Restrepo a Junta Republicana de Jericó. CE. D 211, 3 de mayo de 1909, Medellín. ACER-BUdEA, Colombia.

de Reyes este departamento se había convertido en el segundo foco de poder en Colombia, y la elite regional formada por liberales y conservadores tenían la confianza para encabezar la oposición a Reyes y formar la Unión Republicana (Abel, 1987, p. 81), la cual tenía gran fuerza en Bogotá, lo que representaba un importante respaldo, razón por la cual de este departamento y de sus Juntas Republicanas salió gran número de memoriales, cartas, hojas sueltas, artículos de prensa y toda clase de discursos en contra de lo que consideraban "el gobierno dictatorial de Rafael Reyes". Poco a poco los republicanos de Antioquia y los de Bogotá fueron fortaleciendo su alianza, no sólo entre ellos, sino con las distintas regiones del país, donde llegaron a consolidarse unas formas de sociabilidad política, determinadas especialmente por la prensa y la forma como esta hacía que el discurso republicano circulara y fuera convocando cada día a más miembros en torno a una red que se había logrado establecer a partir de las Juntas Republicanas.

El antioqueño Carlos E. Restrepo se había convertido en uno de los líderes más importantes para encabezar esta propuesta política. Era un personaje conservador que inspiraba confianza entre los diferentes sectores de la sociedad y entre los partidos políticos, teniendo en cuenta que su discurso giraba en torno a la conciliación bipartidista, la tolerancia y la paz nacional, además de contar con el apoyo de liberales como Nicolás Esguerra, Benjamín 
Herrera, Enrique Olaya Herrera, entre otros, que lo posicionaban como uno de los líderes mas influyentes para llegar a consolidar la Unión Republicana.

\section{La Unión Republicana}

La Unión Republicana se presentó como un proyecto de modernización política, que pretendía romper las prácticas tradicionalistas, dictatoriales, y sobre todo la confrontación entre liberales y conservadores. Los actores políticos del republicanismo pertenecían principalmente a las elites de Bogotá y Medellín, a las que poco a poco se fueron sumando líderes del resto del país. Estos líderes republicanos se reagruparon, creando nuevas formas de sociabilidad bajo la articulación entre individuos que compartían ideas e intereses políticos, sin importar que vinieran de partidos distintos. En ese sentido plantearon una construcción discursiva basada en la tolerancia, la conciliación, el progreso, y sobre todo la paz política, como elementos esenciales del orden y la formación de un Estado moderno.

De esta manera se generaron nuevas formas de sociabilidad a partir de la adscripción de los simpatizantes, de la promulgación de ideales, de un proyecto de democracia que demandaba una nueva legislación electoral y que cambiaba los ritmos de la política, haciendo ver que la sociedad colombiana necesitaba evolucionar e insertar nuevos valores que condujeran a la formación ciudadana, participativa, y creadora de cultura política.

Para los líderes republicanos, el 13 de marzo de 1909 representó el momento más importante, de consolidación entre liberales y conservadores bajo el nombre de Unión Republicana. En palabras de Carlos E. Restrepo (1972): "El 13 de marzo de 1909 se verificó de hecho y de derecho esa bella unión de partidos que se llamó Unión Republicana" (p. 409), nombre con el cual pretendieron consolidarse como un tercer partido político, que empezó a estructurarse y organizarse en todo el país para participar en las elecciones del Senado y la Cámara bajo la dirección de las Juntas Republicanas departamentales y municipales.

La Unión Republicana centró su programa en defender y promulgar la soberanía y la integridad del Estado, el sufragio libre, la constitución del cuerpo legislativo de elección popular, la libertad personal, la libertad de prensa, la amortización del papel moneda, el voto como condición correlativamente necesaria al impuesto (Correa, 1996, p. 122), la separación entre Iglesia y Esta- 
do y el rechazo a un Partido Conservador católico. Tal como lo mencionaría Carlos E. Restrepo (1972): "Consagremos los partidos a la política; el catolicismo a la religión", situación que llevó a que la Iglesia ejerciera oposición a la Unión Republicana desde su ejercicio cotidiano y desde periódicos católicos y conservadores. Estos fueron aspectos que consolidaron el discurso republicano y a través de los cuales pretendieron tomar posiciones políticas diferentes a las de los gobiernos anteriores, tanto de la Regeneración como del quinquenio de Reyes, lo que generó tanto simpatizantes, como opositores que se movieron por medio de la prensa y la circulación de información en cartas, telegramas, hojas sueltas, panfletos y circulares, que agitaron y dinamizaron las ideas políticas.

Por una parte, la Unión Republicana vino a ser presentada como una especie de "salvación" entre las hostilidades que vivían los partidos liberal y conservador. En diferentes regiones del país la prensa generó un discurso de aceptación: en Tunja, por ejemplo, La linterna publicó: "la unión ha venido a suavizar las relaciones entre los dos partidos y ha demostrado a los conservadores que el liberalismo es una fuerza viva sin el concurso de la cual no puede darse un paso en el progreso del país", ${ }^{18}$ pero antes en Cartagena ya la prensa había mencionado que "para sostener y llevar a la práctica un ideal político común a todos los partidos históricos de Colombia, se había constituido el Partido Republicano" ${ }^{19}$ Estas ideas también se manifestaban en Bucaramanga donde el periódico La República aseguraba que cuando dos grupos políticos separados por líneas doctrinarias unen sus banderas ante la tiranía y se disponen a la defensa de la libertad, afianzan poderosamente el pedestal de la república. ${ }^{20}$ Así, la prensa y la correspondencia de distintos lugares del país fueron difusoras del discurso republicano, bajo principios de conciliación y de progreso económico, aunque también era fuerte el rechazo al régimen político anterior, lo cual se había convertido en un símbolo de lucha en defensa de la unidad entre partidos.

Asimismo, estaba el discurso de oposición que manifestaba que no era posible esa alianza entre miembros de distintos partidos porque cada uno tenía sus propias ideas, las cuales resultaban contradictorias. Concebían a la Unión Republicana como un mecanismo para debilitar el poder o como

\footnotetext{
18 La Linterna, 24 de septiembre de 1909, Tunja.

19 "Por la Republica”, El Republicano, 30 de abril de 1909, Cartagena.

20 "La Unión Republicana”, La República, 16 de octubre de 1909, Bucaramanga.
} 
oportunismo, particularmente del liberalismo para acercarse al gobierno; por lo que los ataques que recibían eran constantes. Por ejemplo, algunos liberales de Bogotá manifestaban que se había organizado algo que se semejaba a un nuevo partido político llamado Unión Republicana; de muy corta experiencia del que creían que "no es partido, ni es unión, ni es nada", formado por elementos de todas las agrupaciones políticas, en donde no creían que compartieran ni principios, ni prácticas, ni modos de gobierno, sino que su único interés era el derrocamiento del régimen de Reyes. ${ }^{21} \mathrm{~A}$ esto se sumaban conservadores de Ibagué, para quienes la Unión Republicana como fusión era imposible porque tenían ideas totalmente opuestas; resaltaron que esta articulación era una "amalgama insensata, concentración mercantil de los partidos, con el objeto de repartirse a prorrata y entre sí los empleos públicos". ${ }^{22}$ También estaban las declaraciones de un periódico religioso de Medellín que sostenían que era un grupo escaso de personal compuesto de los diversos saldos de los grandes partidos tradicionales, que no sintiéndose bien en las filas donde hasta ayer militaron, se daban cita en la Unión Republicana, donde todos tenían asiento. ${ }^{23}$ Si bien es cierto que la Unión Republicana unía a individuos de distintos grupos, sectores y filiaciones políticas; que uno de sus propósitos fundamentales era derrocar el gobierno de Reyes y que los liberales veían en este movimiento la oportunidad de acceder al gobierno, no se puede desconocer los alcances que tuvo en términos de "modernidad política" con la apertura de nuevos espacios democráticos, la participación ciudadana y la formación de cultura política.

Las elecciones constituyeron desde momentos muy tempranos, tanto el modo fundamental de acceder con legitimidad al gobierno nacional, como de formar parte de la ciudadanía (Irurozqui, 2000, p. 144). Esto no era ajeno en Colombia a la Unión Republicana, que denunciaba la ausencia de los procesos electorales durante el gobierno de Reyes, el carácter ilegítimo y la corrupción que caracterizaba estos comicios.

Las elecciones para el Senado y la Cámara de mayo de 1909 se convirtieron en el escenario propicio para que la Unión Republicana, a través de las Juntas Republicanas, pusiera en marcha su programa político y exigiera al gobierno legitimidad en los procesos, razón por la cual su principal función fue

\footnotetext{
21 “Ni Unión Republicana, ni partido, ni nada”, El Republicano, 24 de abril de 1909, Bogotá.

22 "La locura republicana", Libertad y Orden, 18 de agosto de 1909, Ibagué.

23 "La concentración conservadora”, El Bien Público, 21 de octubre de 1910, Medellín.
} 
adelantar y supervisar los trabajos electorales y presentar las denuncias por irregularidades y fraudes, entre las cuales podemos mencionar casos como el del municipio de Medellín, donde el comité republicano manifiesta "resistencia para entrar a la oficina donde se hacen las inscripciones para votaciones por parte de emisarios del mismo gobierno, quienes hacen una calificación, impidiendo el ingreso de republicanos" ${ }^{24}$ Además, municipios como Titiribí, Jericó, Sofía, Girardota, Sonsón, ${ }^{25}$ entre otros, registraron este tipo de situaciones que evidencian, por un lado, la denuncia de atropellos del gobierno y, por el otro, la actividad de las Juntas Republicanas, en el sentido de evitar el fraude en los comisios para el Senado y la Cámara, pero además de hacer visible la idea de un gobierno corrupto, ilegal, antidemocrático e inconstitucional.

Las elecciones para el Senado fueron realizadas por los colegios electorales, que habían sido elegidos con anterioridad por los concejos municipales, los cuales eran designados por los gobernadores. Aunque los resultados del Senado no fueron favorables para los republicanos, precisamente por su carácter oficial, las elecciones para la Cámara de Representantes realizadas el 30 de mayo de 1909, proclamadas como elección popular, fueron consideradas un triunfo republicano. Mientras que Fernando Correa asegura que "en Antioquia y en todo el país los republicanos ganaron las elecciones a la Cámara; todos los candidatos presentados por las Juntas Republicanas fueron elegidos como representantes" (Correa, 1996, p. 138), Carlos E. Restrepo en su libro Orientación Republicana (1972) dice: "La mayoría de los representantes elegidos por Antioquia para la Cámara de 1909, pertenecían a la Unión Republicana; no así la representación de los otros departamentos, de modo que en el seno de esa Cámara vinieron a quedar equilibrados los elementos republicanos de un lado y del otro los antiguos nacionalistas y reyistas" (p.

${ }^{24}$ Correspondencia Recibida. Denuncia. D157, f 231, 21 de mayo de 1909, Medellín. ACER-BUdeA, Colombia.

${ }^{25}$ En Titiribí se registra una denuncia porque el gobernador de Jericó impartió órdenes de no votar por los republicanos y además se menciona que muchos campesinos que se inscribieron no asistieron a las votaciones. Correspondencia Recibida. D. 158. F. 232, 24 de mayo de 1909, Titiribí; En la municipalidad de Sofía se hace referencia que el gobierno ordenó a los capitanes de cuadrilla que trajeran a los peones a votar pagándoles el día. Correspondencia Recibida. D. 37 f. 51, 31 de mayo de 1909, Sofía; En Girardota la comunicación afirma que el gobierno condicionó a los maestros de escuela para que ejercieran influencia con los padres de familia para que votaran en su favor. Correspondencia Recibida. D, 187, 31 de mayo de 1909. Girardota; En el caso de Sonsón se dice que el gobernador tenía su propio candidato y existía el temor que los electores fueran requeridos por el gobierno nacional para que votaran por determinados personajes. Correspondencia Recibida. 19 mayo de 1909, Sonsón. ACER-BUDEA, Colombia. 
426). Aunque estas dos informaciones resultan un tanto imprecisas, al revisar la prensa, los corresponsales de diarios como El Nuevo Tiempo de Bogotá, La Organización y República, de Medellín, arrojan datos que permiten determinar que, efectivamente, la Cámara a diferencia del Senado tuvo una representación más equitativa por parte de gobiernistas, bloque liberal y republicanos.

Para la Unión Republicana, los resultados de las elecciones de representantes a la Cámara podían leerse como satisfactorios, y aunque los gobiernistas se adjudicaran el triunfo, sabían que las elecciones de mayo de 1909 habían posicionado a la Unión Republicana como una fuerza opositora. Fue después de las elecciones del 30 de mayo que Reyes decidió salir del país y dejar como presidente encargado a Jorge Holguín. En este sentido las elecciones de mayo de 1909 fueron el evento clave para que la Unión Republicana lograra posicionarse en la escena política y, especialmente, para terminar de derrumbar el gobierno de Reyes, que estaba en serias dificultades, en parte, debido a la oposición que habían hecho los mismos republicanos. De esta manera la coalición había tenido uno de los mayores logros; así, con posterioridad a la salida de Reyes se inició otra etapa para el "Republicanismo" como tendencia política.

\section{El Republicanismo desde sus redes de información y comunicación}

Para estudiar las redes de información y comunicación creadas por los republicanos hacia 1908-1910, es conveniente analizar las formas de sociabilidad para ver como a partir de ellas se definió un nuevo movimiento político llamado Unión Republicana. Los lazos de sociabilidad creados por la Unión Republicana van más allá del establecimiento de unas redes, que para este caso fueron las Juntas Republicanas tanto nacional, como departamentales o municipales. Se trató más bien de individuos que encontraron nuevas formas de relacionarse y asociarse de manera voluntaria por medio de reuniones, manifestaciones públicas, tertulias, el intercambio de correspondencia y la emergencia y difusión de la prensa, que transmitieron nuevas ideas y un discurso orientado hacia la modernidad política.

En este sentido, es importante hacer referencia a Pilar González (2008) quien precisa la distinción entre sociabilidad y red. "La sociabilidad remite a prácticas sociales que ponen en relación un grupo de individuos que efectivamente participan de ellas y apuntan a analizar el papel que pueden jugar esos vínculos; la red, remite a espacios de interacción social [...] que no implica 
que todos los individuos que participan a la red se conozcan ni que compartan espacios de sociabilidad" (p. 10). En este caso lo que estudiamos son las formas de sociabilidad que se generaron al interior de la Unión Republicana, para ver cómo contribuyeron a definir una red política que poco a poco fue permeando con sus ideas a otros sectores de la sociedad como los industriales, obreros y campesinos.

Inicialmente, se trató de una red que estuvo conformada por líderes políticos liberales y conservadores ubicados en Bogotá y Medellín. En el primer caso hacemos alusión a Guillermo Quintero Calderón (conservador), Nicolás Esguerra (liberal), Carmelo Arango (liberal), Daniel J. Reyes (conservador), Adolfo León Gómez (liberal), José Vicente Concha (conservador) y Enrique Olaya Herrera (liberal); y para Medellín personajes como Carlos E. Restrepo (conservador), César Piedrahita V. (liberal), Juan Pablo Gómez O., Juan Bautista Peláez, Eduardo Correa Uribe, Antonio José Montoya, Mariano Ospina Vásquez, Pedro Nel Ospina (conservador), Tomas O. Eastman (liberal) y Santiago Pérez Triana (liberal), que aunque se encontraba en Londres, mantenía estrecha comunicación con los republicanos Carlos E. Restrepo y Pedro Nel Ospina. En este sentido, identificamos algunos vínculos entre estos líderes que conformaron la Unión Republicana; para empezar, hacemos referencia a que estos personajes se movían en tres campos específicos: político, empresarial y periodístico, y que además coincidían en el rechazo hacia el gobierno de Rafael Reyes y la defensa de un proyecto de Estado moderno.

Para el caso de Bogotá, el conservador Guillermo Quintero Calderón y el liberal Nicolás Esguerra, director del Diario Republicano en 1912, fueron dos personajes que se movieron en el ámbito político nacional, razón por la cual los ciudadanos de la capital los eligieron para que se encargaran del trabajo electoral del Senado y la Cámara de mayo de 1909, junto con Carmelo Arango.

Señores Dr Nicolás Esguerra, General Guillermo Quintero Calderón y Doctor Carmelo Arango. Los infrascritos ciudadanos colombianos, miembros de los diversos partidos, deseosos de conservar a todo trance la paz y la concordia de la Nación mediante el restablecimiento de las instituciones republicanas, hemos acordado nombrar a ustedes para que formen el centro encargado de dirigir los trabajos eleccionarios del próximo Congreso. ${ }^{26}$

${ }^{26}$ Thalía, 26 de marzo de 1909, Bogotá. 
Esta designación revistió gran importancia, porque de acuerdo con prensa capitalina como El Nuevo Tiempo y Thalía, este nombramiento lo firmaron más de 4000 ciudadanos entre los que estaban José Vicente concha, Adolfo León Gómez, Luis Rubio Sáiz, Juan B. Quintero, Miguel Abadía Méndez, José A. Llorente, Daniel J. Reyes, Ricardo Jaramillo, por nombrar algunos de los firmantes que hacían parte de una amplia red instaurada en la capital para hacer frente a las elecciones y al gobierno de Rafael Reyes.

Para el caso de Antioquia la sociabilidad estuvo dada por vínculos de amistad y de negocios, en donde la política fue elemento indispensable para reafirmarse como departamento en desarrollo y apuntarle a la Unión Republicana como movimiento político que agrupara a un importante número de líderes. El principal representante del republicanismo en Antioquia fue Carlos E. Restrepo, quien además de ser abogado, periodista y escritor, tuvo una librería en Medellín en donde recibió publicaciones de sus amigos y las ayudó a difundir tanto en Antioquia como en varios lugares del país. Uno de los primeros diarios que dirigió en compañía de Pedro Nel Ospina fue Vida Nueva hacia 1904 y luego como miembros de la Junta Republicana de Antioquia crearon el periódico República en 1909, que se convirtió en su principal órgano de difusión. Asimismo fue gerente de la Compañía Antioqueña de Tejidos, y cuando fue elegido presidente de Colombia en 1910 se desempeñaba como presidente de la Cámara de Comercio de Medellín, por lo que la relación de los negocios y la política se hacían condición indispensable como líder de la Unión Republicana.

Pedro Nel Ospina y Mariano Ospina, conservadores influyentes de Antioquia, fueron, también, miembros de la Cámara de Comercio, consolidaron una empresa familiar bajo el nombre de Ospina Hermanos, dedicada a la producción y exportación de café e importantes inversiones en el alumbrado público de Bogotá y el Ferrocarril de Antioquia. Pedro Nel, además, participó en la Compañía de instalaciones eléctricas de Medellín, en la Cervecería Antioqueña y en la Compañía Antioqueña de Tejidos. A los hermanos Ospina y a Carlos E. no sólo los unía su condición de antioqueños, sino las relaciones comerciales que mantenían y que procuraban fortalecer desde una mayor intervención política, que condujera al desarrollo económico y progreso de Colombia. Para lograr dicho progreso centraron su atención en temas relacionados con vías de comunicación, que eran indispensables para el fortalecimiento de la industria naciente; la explotación de riquezas minerales como el 
hierro, el carbón, el oro y la plata, consideradas de incalculables proporciones y de gran importancia para salir del atraso y pobreza del país.

En este grupo también se encontraba al escritor, periodista, poeta y hombre de negocios Santiago Pérez Triana, bogotano de nacimiento, pero que vivió la mayor parte de su vida en el exterior, especialmente en Londres, según lo registra la correspondencia de la época, desde donde seguía con mucho interés los asuntos de orden nacional relacionados con la deuda externa, la soberanía nacional, los tratados con Estados Unidos, las vías de comunicación, los ferrocarriles, y otros temas que logró recopilar en sus libros: Desde lejos (Madrid, 1907), Desde lejos y desde cerca. Asuntos colombianos (Londres, 1909), y Eslabones sueltos (Londres, 1910), tres publicaciones que trataban temas y pautas que Pérez Triana consideraba indispensables para lograr el progreso del país, así como duras críticas al gobierno de Rafael Reyes, lo cual provocó la censura por parte del gobierno, pero logró acercarlo a los Republicanos y convertirse en un líder importante de este movimiento político.

El libro Desde lejos circuló principalmente en Medellín, pues "los ejemplares enviados a Bogotá fueron en su mayor parte secuestrados e incinerados por el Administrador General de Correos" ${ }^{27}$ Sin embargo, el libro fue enviado al presidente Rafael Reyes, y en las primeras páginas se encuentra una carta abierta de Santiago Pérez Triana (1907) explicando el motivo de su publicación y su intención "porque tal vez puedan contribuir á inclinar la atención pública hacia asuntos de positiva importancia para la Nación”. A pesar de la censura que tuvo este libro por parte del gobierno, buscaron estrategias para circularlo, como se aprecia en la correspondencia enviada a Restrepo:

He dado orden para que, desde diversos puntos del continente, y envueltos en otros libros, sean enviados ejemplares de Desde Lejos a las personas cuyos nombres me indica Vd. Además, creo que he logrado arreglar que le envíen á Vd. un paquete de 10 ejemplares desde un punto de la República. El temor siempre presente en el ámbito de los colombianos de que su correspondencia sea violada por nuestro paternal gobierno me impide ser más preciso en estos datos. ${ }^{28}$

${ }^{27}$ Carta de Santiago Pérez Triana. Correspondencia Recibida. Caja 9, D 40, 29 de mayo de 1908, Londres. ACER-BUDEA, Colombia.

${ }^{28}$ Carta de Santiago Pérez Triana. Correspondencia Recibida. Caja 9, f. 7, 17 de agosto de 1908. París. ACER-BUdEA, Colombia. 
Este tipo de acciones daban cuenta de la forma como las ideas iban circulando y encontrando otros mecanismos además de la prensa y la correspondencia, en este caso los libros y documentos que llegaban a las personas más influyentes de la vida política nacional, que además tenían eco en las editoriales de los periódicos y eran motivo de discusión en cartas y telegramas.

A este grupo de hombres letrados, políticos y de negocios se sumó el abogado, periodista y diplomático Enrique Olaya Herrera, reconocido por su labor periodística desde niño con el periódico El Patriota en Guateque (Boyacá), y en el periodismo activo haciendo reportajes para el periódico el autonomista de Rafael Uribe Uribe y Ricardo Tirado Macías. Pasada la guerra civil de los Mil Días fundó El Comercio y luego se destacaron sus escritos en el Mercurio, Gaceta Republicana y El Diario Nacional (Mira, 2014). Su principal incursión como político fue el 13 de marzo de 1909, cuando cautivó a los más jóvenes con un discurso pronunciado en la plaza de Bolívar, convirtiéndose en uno de los mayores activistas de la Unión Republicana.

Como se puede ver, estos líderes compartían una carrera política, una experiencia periodística y una trayectoria en los negocios que los posicionó como elite intelectual y económica con intención de incidir en la opinión pública, con una nueva visión de país en que se reivindicaran la democracia, las libertades y se proyectara al país en términos de modernización. Esto generó nuevas formas de percibir al sujeto político al reivindicar la democracia y la ciudadanía, a la vez que fomentó nuevas manifestaciones en la política y en las relaciones económicas, teniendo en cuenta una concepción moderna de la sociedad.

Estos personajes hicieron posible que la prensa se convirtiera en un actor político y en un espacio de opinión pública, que le dio base a una red de sociabilidad creada para ejercer un poder político, manifestado a partir de las Juntas Republicanas como escenarios de control, de organización y de expresión, que buscaban obtener su propia legitimidad. Entre la prensa y la correspondencia se generó un vínculo importante en el ejercicio de la opinión pública, hubo una proliferación de periódicos republicanos, así como de prensa opositora, que defendía la política gubernamental, donde cada quien empleaba sus argumentos, sus recursos y lenguajes variados, así como sus estrategias de distribución que le posibilitaran ampliar su grupo de lectores.

Entonces la prensa se convirtió en una herramienta de lucha, pero también de unidad. Propició redes de comunicación que llevaban un discurso sostenido por los libros, los documentos, las cartas, las editoriales, los panfletos, las hojas sueltas, memoriales y demás elementos que llegaban a los cafés, 
a las plazas, a los mercados, a los salones, librerías y demás espacios públicos que permitieron la circulación de las ideas políticas, no sólo entre la elite, sino también entre los sectores populares que estaban insertos en estos lugares.

En el cuadro 5 enlistamos los periódicos republicanos en diferentes ciudades y municipios de Colombia, que fueron los encargados de circular el discurso republicano.

Estos periódicos de tendencia republicana, en su mayoría, se declaraban órganos difusores de las ideas republicanas, como es el caso del periódico República de Medellín, La Unión Republicana de Bogotá, La República de Bucaramanga, Ayer y Hoy de Málaga, El Amigo del Pueblo de Cali, por mencionar algunos que fueron creados por las Juntas Republicanas de sus ciudades y municipios. Compartieron en sus publicaciones circulares, cartas, manifestaciones, y en general el discurso republicano que contenía en sus ediciones artículos con temas muy similares, entre los que encontramos, el programa de la Unión Republicana, la organización de las Juntas Republicanas, circulares informativas sobre elecciones, abusos cometidos por el gobierno nacional y discursos pronunciados por líderes republicanos. En este sentido, podemos apreciar cómo la prensa republicana fue una red de información y comunicación que consolidó un grupo de líderes, que a su vez crearon las Juntas Republicanas, y que paulatinamente vincularon a miles de ciudadanos en torno a la Unión Republicana en todo el territorio nacional.

Esto se puede dar a través de lo que Loaiza Cano (2016) llama "los dispositivos reguladores de la vida pública”, refiriéndose específicamente al periodismo y a su papel en la comunicación y discusión de las leyes y demás ejecutorias gubernamentales; como instrumentos publicitarios que ayudaron a la formación de una comunidad política dispuesta a la discusión pública permanente (p. 191). Así, los distintos sujetos como los artesanos, los obreros, los curas, los políticos, los comerciantes, la elite, tenían acceso a la prensa y participaban de ella, a través, de las conversaciones públicas, las reuniones, la distribución de periódicos y hojas sueltas, que normalmente contenían discursos partidistas, ideas electorales y denuncias que buscaban sumar simpatizantes, de uno y otro bando que en definitiva competían por la opinión pública, desde las distintas formas de sociabilidad. Entonces, a través de la prensa no sólo se configuró un discurso político, sino que se dio apertura a redes y espacios públicos de sociabilidad, donde varios de estos periódicos editados en las principales ciudades pudieron distribuirse también en las regiones, a través de canjes; en otras ocasiones, los diarios publicaron artículos 


\section{Cuadro 5. Prensa Republicana en Colombia}

Ciudad

Barranquilla Atlante; El Grito de la Juventud; Génesis

Bogotá

y 2; Don Quijote; El Contemporáneo; El Diario; El Mensajero;

El Popular; El Republicano; Espíritu Nuevo; Honor y Patria;

La Civilización; La Joven Colombia; La Pluma Libre; La Protesta; La Revista; La Unión Republicana; Prensa Libre; Voz del País; 13 de Marzo; Thalía y Zig Zag

Bucaramanga Vida Nueva; La República

Buga

El Escudo; Notas Republicanas

2

Cali

El Fagocito, La Orientación Republicana; Los Derechos del Pue-

blo; Unión Republicana; El Amigo del Pueblo

Cartagena

Cúcuta

El Gráfico; El Verbo; La Culebra; La Verdad; Informaciones

Honda

Ibagué

El Republicano, La Actualidad

5

2

2

1

Ipiales

La Cohesión

El Obadeño; La Voz de la Frontera; Unión Republicana

3

La Mesa

Gaceta Republicana

1

Málaga

Ayer y Hoy; Voz Republicana

2

Manizales Blanco y Negro; Burbujas; El Combate; El Criterio; El Or-

10

den; El Piloto; El Taller; Labor y Paz; Pabellón Azul, Unión

Republicana

Medellín Actualidades; La Joven Colombia; República; República

Palmira

La Juventud Republicana; Voz Republicana

Pasto

El Sur Republicano; La Unión Republicana; La Actualidad

2

Pereira

El Artesano; El Eco Republicano

3

Quibdó

Ecos Republicanos; La Bandera

2

Tuluá

Hoja Republicana

2

Yarumal Pax

3

0

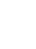

(1)


de periódicos nacionales o regionales, permitiendo compartir la información y en definitiva el discurso político.

De esta manera se fueron tejiendo los lazos entre los líderes que habitaban en Medellín, Bogotá, Manizales, Barranquilla, Cali, y otras ciudades principales y pueblos pequeños, que paulatinamente sumaban simpatizantes y fortalecían su coalición entre liberales y conservadores bajo la alianza Republicana.

La articulación de las redes que se generaron a partir de las Juntas Republicanas implementó nuevos vínculos entre líderes políticos en las diversas regiones del país, que paulatinamente fueron defensores de la democracia, de las libertades, de la prensa libre, de la libertad de comercio bajo la idea de progreso. Con estas ideas los líderes influyeron en la política local generando mayores adhesiones entre trabajadores, artesanos, y otros actores sociales que se conectaron a través de la prensa, la correspondencia, la asistencia a movilizaciones, en las elecciones y en los espacios públicos donde se socializaban las ideas republicanas referidas a la modernización, que incidieron en la configuración de un nuevo sujeto que afectó la toma de decisiones políticas (Price, 1994, p. 22), con mayor independencia frente a las ideas de gobierno.

\section{CONCLUSIONES}

El periodo de Rafael Reyes, conocido como el Quinquenio de Reyes (19041909), se consolidó como un gobierno autoritario y dictatorial que dio pie a que líderes políticos y económicos, pertenecientes a los partidos liberal y conservador de distintas regiones del país y especialmente de Bogotá y Medellín, se organizaran como movimiento político de oposición bajo el nombre de Unión Republicana, organizado y estructurado a partir de Juntas Republicanas Departamentales y Municipales, que cumplieron un papel importante no sólo en la salida del mandatario de la presidencia, sino en la consolidación de un nuevo proyecto de Estado, caracterizado por la modernidad política, la democracia, la tolerancia, la conciliación bipartidista y la Paz, como condición necesaria para el progreso.

Las Juntas Republicanas se establecieron en un número considerable de municipios de Colombia y, con mayor fuerza, en Bogotá, donde se creó la Junta Republicana Nacional, así como en el departamento de Antioquia, donde se ubicó un gran número de líderes con trayectoria política de oposi- 
ción al gobierno de Reyes. Estas Juntas Republicanas fueron las encargadas de organizar y estructurar la Unión Republicana a nivel nacional, bajo un discurso político divulgado por la prensa y la correspondencia, que sintetizaban la acción de las distintas Juntas locales, que terminaron por convertirse en una poderosa red de comunicación, bajo prácticas de sociabilidad determinadas por reuniones, manifestaciones, discursos, ideas, denuncias y demás lecturas y lenguajes que crearon y compartieron alrededor de sus líderes.

\section{LISTA DE REFERENCIAS}

Abel, C. (1987). Política, Iglesia y partidos en Colombia, 1886-1953. Bogotá: faEs-Universidad Nacional de Colombia.

Acuña, O. (2017). La reforma constitucional colombiana de 1910 y el sistema electoral (1910-1914). Historia y Memoria, 14, 97-126. DoI: https://doi.org/10.19053/20275137. n14.2017.5817

Adarve, L. (2010). Gobernar, reformar y encarcelar: La construcción del orden en Colombia, 1888-1910. Universidad Nacional de Colombia. Recuperado de https://repositorio. unal.edu.co/handle/unal/55738

Agulhon, M. (2009). El círculo burgués. La sociabilidad en Francia, 1810-1848. Buenos Aires: Siglo XXI Editores.

Álvarez, J. (1995). El republicanismo en Barranquilla: 1909-1914. Dinamización de la Política. Huellas, Revista de la Universidad del Norte, 45, 30-40.

Brugman, C. (2001). El fracaso del republicanismo en Colombia, 1910-1914. Historia Crítica, 21, 91-110. DoI: https://doi.org/10.7440/histcrit21.2001.08

Correa, F. (1996). Republicanismo y reforma constitucional 1891-1910. Medellín: Facultad de Ciencias Sociales y Humanas-Universidad de Antioquia.

Duque, J. (2011). La reforma constitucional de 1910. Constantes institucionales, consensos y nuevas reglas. Papel Político, 16(1), 185-212.

Flórez, L. (1997). Modernidad política en Colombia. El republicanismo en el Valle del Cauca 1880-1920. Santiago de Cali: Facultad de Humanidades-Universidad del Valle.

Furet. F. (1978). Pensar la revolución francesa. París: Ediciones Petrel.

González Bernaldo. P. (2008). La "sociabilidad" y la historia política. Nuevo Mundo. Mundos Nuevos. Recuperado de http://journals.openedition.org/ nuevomundo/24082

Guerra, F. (1989). Hacia una historia política: actores sociales y actores políticos. Anuario del IEHS, 4. 
Irurozqui Victoriano, M. (2000). "A bala, piedra y palo". La construcción de ciudadanía política en Bolivia. 1826-1952. España: Diputación de Sevilla.

Loaiza Cano. G. (2016). Temporalidad, sociabilidad y democracia (Colombia y su siglo XIX). Historia Caribe, XI(28), 177-210. DoI: http://dx.doi.org/10.15648/hc.28.2016.7

Melo, J. (1989). De Carlos E. Restrepo a Marco Fidel Suárez. Republicanismo y gobiernos conservadores. En Nueva Historia de Colombia. (Vol. I). Bogotá: Editorial Planeta.

Mesa, D. (1982). La vida política después de Panamá. 1903-1922. En Manual de historia de Colombia. (T. III). Bogotá: Procultura.

Mira Betancur, C. (2014). Enrique Olaya Herrera y su época. Desarrollo político y consolidación del Estado colombiano. (Tesis de maestría). Universidad Católica de Colombia, Bogotá.

Pérez Triana, S. (1907). Desde lejos (Asuntos colombianos). Londres: Imprenta de Wertheimer, Leal y Cía.

Price, V. (1994). La opinión pública. Esfera pública y comunicación. Barcelona: Editorial Paidós.

Restrepo, C. E. (1972). Orientación republicana. (2 vols.). Medellín: Banco Popular.

Rubiano Muños, R. (2011). Carlos E. Restrepo y el republicanismo de 1910. A los 101 años de la reforma constitucional, polémicas y debates políticos. Medellín: Universidad de Antioquia. Recuperado de http://bibliotecadigital.udea.edu.co/bitstream/10495/4301/1/RubianoRafael_2011_CarlosRestrepoRepublicanismo.pdf

Sanín Cano, B. (2015). Administración Reyes (1904-1909). (Colección Memoria Viva. Unidad de Patrimonio Cultural e Histórico). Bogotá: Universidad del Rosario.

Sourdis, A. (2017). De los conservadores históricos y nacionalistas a la Unión Republicana. Tres etapas en la construcción del Estado. Memoria. Revista Institucional del Archivo General de la Nación de Colombia, 17, 9-35. Recuperado de

http://www.archivogeneral.gov.co/sites/default/files/Estructura_Web/5_Consulte/

Recursos/Revista_memoria/Memoria17.pdf

Suárez Mayorga, M. (2017). La construcción de la nación colombiana a la luz del modelo porfirista. Secuencia, 98, 99-129. DoI: https://doi.org/10.18234/secuencia. v0i98.1357 


\section{OTRAS FUENTES}

\section{Archivo}

ACER-Budea Archivo Carlos E. Restrepo-Biblioteca Universidad de Antioquia, Colombia.

\section{Periódicos}

Ayer y Hoy, Málaga.

El Amigo del Pueblo, Cali.

El Bien Público, Medellín.

El Nuevo Tiempo, Bogotá.

El Republicano, Cartagena.

El Republicano, Bogotá.

La Linterna, Tunja.

La República, Bucaramanga.

La Unión Republicana, Bogotá.

Libertad y Orden, Ibagué.

República, Medellín.

Thalía, Bogotá.

Zigzag, Bogotá. 